Original Article

\title{
Evaluating the Anticancer Effects of High-Dilution Preparations of Carcinogens such as HIV virus, Hepatitis $C$ virus, Ethanol and Cancer Tissues in in-vitro models
}

\author{
Rajesh Shah \\ Department of research, Life Force, Mumbai, India \\ sanjivak@gmail.com - https://orcid.org/0000-0002-1263-9077
}

\begin{abstract}
Cancer is one of the leading causes of mortality. The recent experiments with high-diluted preparations have shown anticancer effects in in-vitro and vivo models. The fundamental principle of homeopathy suggests that the substances capable of producing certain diseases may have a capacity to alter the same disease if used in the ultra-dilute-potentized form. This hypothesis led to certain carcinogens for examining their potential anticancer efficacy. Sulforhodamine B assay helps determine the cytotoxicity in cell-based studies in evaluating anticancer agents. The protocol involved preparation of homeopathy dilutions, incubation of cells with homeopathy dilutions, SRB binding, and absorbance measurement. Cells were treated with 30 potencies of HIV nosode, Hepatitis $\mathrm{C}$ nosode, Carcinosin, Cancer nosode, and Ethanol along with positive control (Adriamycin). The preparations were tested in HeLa, HepG2, A549, MCF 7, T 24, Jurkat, SCC 40, and HL-60 cell lines. The homeopathic preparations have shown the anticancer activity measured as percentage growth inhibition. All the homeopathic preparations studied exhibited anticancer activity on HeLa, HepG2, A 549, T 24, and HL-60 cells. Carcinosin showed anticancer activity on the SCC 40 cells. Hepatitis C nosode, Carcinosin, and Cancer nosode have demonstrated the anticancer activity on breast cancer cell line MCF-7. None of the preparations exhibited anticancer activity on Human Leukemia Cell Line. High-dilution, potentized preparations of certain carcinogens have demonstrated anticancer, cytotoxic effects in the cell-line model, supporting the rationale of the fundamental homeopathic principle the Law of Similars, opening windows to its broader applications in healthcare.
\end{abstract}

Keywords: Cancer, Homeopathy, HIV nosode, Hepatitis C nosode, Cancer nosode, Ethanol, Law of similar

\section{Introduction}

Cancer is a complex disease yet not fully treatable, calling for newer therapeutic options. Some recent studies with high-dilution homeopathic drugs have demonstrated anticancer effects in cell line models [1.2.3.4]. In addition, cancer regression in animal models [5] has been demonstrated using high-dilution preparations. More research is encouraged in this direction.

The system of homeopathy was introduced by Samuel Hahnemann, incidentally in the same year 1796 when Edward Jenner [6] introduced vaccinations. Both the approaches are based broadly on the observation that the substances (or organisms) capable of producing diseases in humans also possibly have the ability to alter the same illness if administered in an attenuated form (in case of vaccines) or potentized state in case of homeopathy. In homeopathy, this observation is collated as the Law of Similars. In addition, certain known carcinogens have been selected to substantiate the basic homeopathic principle for examining their potential anticancer efficacy.

The nosodes are broad-spectrum, widely used homeopathic preparations sourced from biological materials such as cultures or clinical samples of microorganisms (e.g., bacteria, fungi, and viruses) or 
parasites, diseased tissues (cancerous tissues), or decomposition products from humans or animals [7]. Some nosodes have exhibited anti-disease activity against the diseases they were sourced. For example, the nosodes prepared from the HIV virus [8], Hepatitis C virus [9], and Plasmodium falciparum parasites [10] have shown respective anti-disease activities in clinical trials or cell-line models, validating the Law of Similars.

HIV infection-associated malignancies are common. The HIV virus depresses the immune system and may potentially induce cancers such as Kaposi sarcoma, Non-Hodgkin lymphoma, and cervical cancer [11]. In addition, the Hepatitis $\mathrm{C}$ virus-infected individuals are at higher risk of developing liver cancer [12]. Ethyl alcohol (C2H60)(subsequently called as Ethanol) has been classified as Group I carcinogen by the International Agency for Research on Cancer (IARC)[13) which can induce female breast, colorectum, larynx, liver, esophagus, oral cavity, and pharynx cancers [14]. As per the "Law of Similars" principle, the HIV virus, the Hepatitis C virus, and Potentized Ethanol may potentially work against malignancies if administered in the high-dilution, potentized dose. Our earlier studies with Khuda-Bukhsh et al. have corroborated this principle by demonstrating anticancer effects of the HIV nosode [15] and Hepatitis C nosode [16] in cell-line models. Therefore, we decided to repeat the part of the study and add three more medicinal substances (Potentized Ethanol and new Cancer Nosode) and one of the famous, old homeopathic medicines prepared from undocumented cancer tissues (called Carcinosin) for examining their potential anticancer effects.

In-vitro cell-based cytotoxicity assay promises to be a practical, reliable and rapid method for demonstrating chemotherapeutic drug activity [17]. The MTT/MTS [18] and sulforhodamine B (SRB) assays are widely used techniques for measuring drug-induced cytotoxicity and cell proliferation for large-scale drug-screening applications [19]. Skehan and colleagues developed the SRB assay based on the SRB dye's ability to bind electrostatically and in a pH-dependent manner on protein basic amino-acid residues. Under mild acidic conditions, SRB binds to protein basic amino-acid residues of trichloroacetic acid (TCA)-fixed cells. It can be quantitatively extracted from cells and solubilized for optical density (OD) measurement by weak bases such as Tris base. Results of the SRB assay were linear with the number of cells and the cellular protein measured at cellular densities in 96-well microtiter plates ranging from 1 to $200 \%$ of confluence [20]. The SRB method is appropriate, sensitive and the endpoint is colorimetric, nondestructive, and indefinitely stable. This method is used for cell density determination based on the measurement of cellular protein content. The method described here has been optimized for the toxicity screening of compounds to adherent cells in a 96-well format [21].

\section{Materials and methods}

\section{Procuring the medicinal substances}

HIV nosode (prepared using sera of HIV type I and type II virus, obtained from HIV infected patients, protocol number LF/001/09) [7], Hepatitis C nosode (prepared using sera of HCV type I and type III virus, obtained from HCV infected patients, protocol number LF/002/09) [8], and Cancer nosode have been developed by the author in the recent years by following the HPI (Homoeopathic Pharmacopeia of India) and other guidelines [22]. Cancer nosode was prepared by the author from several cancer tissues, including Squamous cell carcinoma (skin), Adenocarcinoma (rectum), and more. In addition, signed Informed consents (approved by the ethics committee) of donors to use biological materials (sera and tissues) were obtained and documented. Carcinosin is a known homeopathic nosode procured from the market, which does not have adequate source information. (SBL, batch no. H1413685). Ethanol (92\% dispensing alcohol as per HPI standards) was prepared up to the 30c potency by the author. The ethics committee approved the use of nosodes for the in-vitro SRB assay, protocol number ACTREC/LF/14/15). 


\section{Homeopathic preparations}

The cell lines were treated with the 30c potency of the following high-dilution preparations:

a. HIV nosode (HNOD07) prepared from type I and type II HIV-infected individual's serum as per the Homeopathy Pharmacopoeia of India method (7).

b. Hepatitis C nosode (HCNOD8) prepared from type I and type III Hepatitis C infected individual's serum as per the Homeopathy Pharmacopoeia of India method (8).

c. Carcinosin (CSIN01) purchased from Sharda Boiron Laboratories Ltd. (SBL).

d. Cancer nosode (CNOD02) prepared from cancer tissues as per the Homeopathy Pharmacopoeia of India method.

e. Ethanol (APOT03) purchased from Merck, Germany, which was potentized.

f. Adriamycin/ADR (Doxorubicin as a positive control).

g. Cell control.

All above preparations were diluted using alcohol as a vehicle purchased from Merck (purity of 99.9\%) in aseptic conditions and potentized using a standardized electro-mechanical potentizer.

\section{Cell Lines}

Human cervical cancer cell line (HeLa), Hepatoma cell line (Hep-G2), Lung cell carcinoma (A-549), Breast cancer cell line (MCF-7), Bladder cancer cell line (T-24), Leukemia cell line (Jurkat), Oral squamous cell line (SCC-40), and Myeloid Leukemia cell line (HL-60) were used in the study.

\section{Selection of dose}

Cell lines were treated with the 30c potency of HIV nosode, Hepatitis C nosode, Carcinosin, Cancer nosode, and Potentized Ethanol using the dilutions 1:10, 1:05, 1:01, and direct (30c).

\section{SRB assay}

The SRB assay technique as per the therapeutic development program by National Cancer Institute was used as a reference. In addition, the Advanced Centre for Treatment, Research, and Education in Cancer (ACTREC) provides commercial services for screening anticancer drugs. Therefore, the work was done through the customized service at ACTREC.

The cell lines were grown in RPMI 1640 (Roswell Park Memorial Institute) medium containing 10\% fetal bovine serum and $2 \mathrm{mM}$ L-glutamine. For present screening experiments, the cells were cultivated into 96-well microtiter plates in $100 \mu \mathrm{L}$ at plating densities of cell count +5000 . The initial cell seeding density was selected depending on the doubling time of the individual cell lines (23). Plates were incubated at $37^{\circ} \mathrm{C}, 5 \% \mathrm{CO} 2,95 \%$ air, and $100 \%$ relative humidity for 24 hours before the addition of experimental drugs.

The homeopathic samples (30c potency; direct) were stored at room temperature, diluted to 1:10, 1:05, and 1:01 with vehicle (un-potentized alcohol). Finally, aliquots of $10 \mu \mathrm{l}$ of these different homeopathy dilutions were added to the appropriate well already containing $90 \mu \mathrm{l}$ of the medium, resulting in the required final drug concentrations, i.e. $10 \mu \mathrm{g} / \mathrm{ml}, 20 \mu \mathrm{g} / \mathrm{ml}, 40 \mu \mathrm{g} / \mathrm{ml}, 80 \mu \mathrm{g} / \mathrm{ml}$.

After compound addition, plates were incubated at standard conditions for 48 hours, and the assay was terminated by the addition of cold Trichloroacetic Acid (TCA). Cells were fixed in-situ by the gentle addition of $50 \mu \mathrm{l}$ of cold $30 \%$ (w/v) TCA (final concentration, $10 \%$ TCA) and incubated for 60 minutes at $4{ }^{\circ} \mathrm{C}$. The supernatant was discarded; the plates were washed five times with water and air-dried. The SRB solution $(50 \mu \mathrm{l})$ at $0.4 \%(\mathrm{w} / \mathrm{v})$ in $1 \%$ acetic acid was added to each of the wells, and plates were incubated for 20 minutes at room temperature. After staining, the unbound dye was recovered, and the residual dye was removed by washing five times with $1 \%$ acetic acid. The plates were air-dried. The bound stain was subsequently eluted with a $10 \mathrm{mM}$ trizma base, and the absorbance was read on a plate reader at a wavelength of $540 \mathrm{~nm}$ with $690 \mathrm{~nm}$ reference wavelength. 
Percent growth was calculated on a plate-by-plate basis for test wells relative to control wells. Percent growth was expressed as the ratio of average absorbance of the test well to the average absorbance of the control wells X 100.

Using the six absorbance measurements [time zero (Tz), control growth (C), and test growth in the presence of drug at the four concentration levels (Ti)], the percentage growth was calculated at each of the drug concentrations levels. Percentage growth inhibition was calculated as [Ti/C] x $100 \%$.

Growth inhibition of $50 \%$ (GI50) is calculated from [(Ti-Tz)/(C-Tz)] x $100=50$, which is the drug concentration resulting in a 50\% reduction in the net protein increase (as measured by SRB staining) in control cells during the drug incubation. The drug concentration resulting in total growth inhibition (TGI) is calculated from $\mathrm{Ti}=\mathrm{Tz}$.

The experiment was conducted in triplicate for each cell line to validate the results.

\section{Results}

Images 1-3 showing cell growth after SRB staining in A-549, MCF-7 and T-24 cell line indicating efficacy of test samples compared with controls.

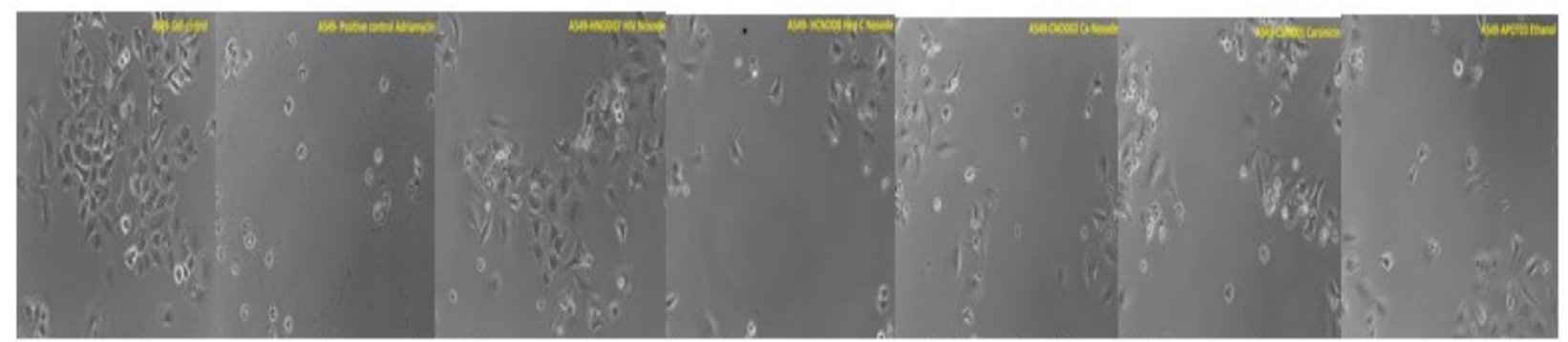

Image 1: Efficacy on A-549 (Lung cell line): Hep C, HIV, Carcinosin, Ca- Nosode and Ethanol with positive and cell controls

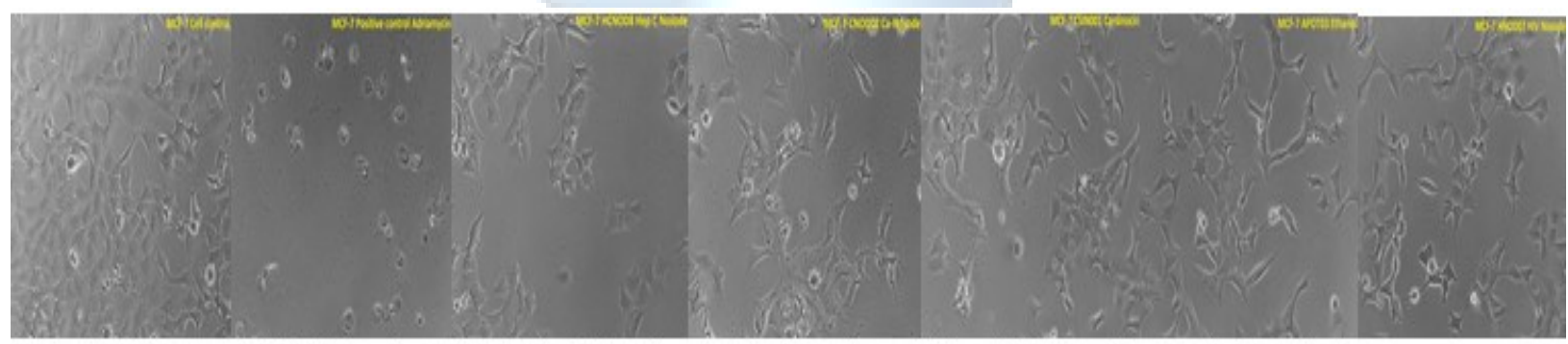

Image 2: Efficacy on MCF 7 (Breast cell line): Hep C, Carcinosin, Ca- Nosode and Ethanol with positive and cell controls

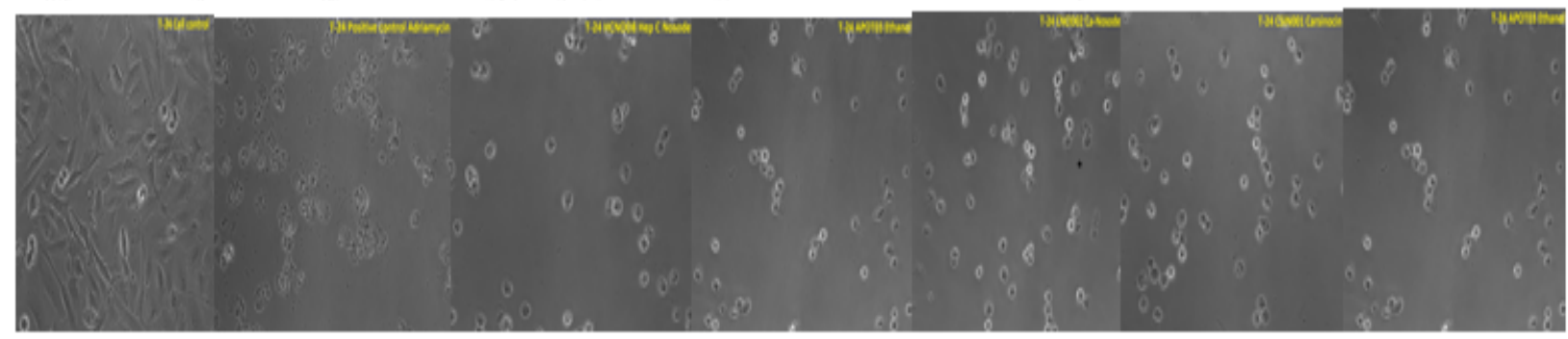

Image 3: Efficacy on T-24 (Bladder cell line): Hep C, HIV, Carcinosin, Ca- Nosode and Ethanol with positive and cell controls

The figures 1 to 9 represent the percentage control growth studied in all cell lines for HIV nosode, Hepatitis C, Carcinosin and Cancer nosode, Potentized Ethanol in 30c dilution, as 1:10, 1:05, 1:01 and direct (30c). 


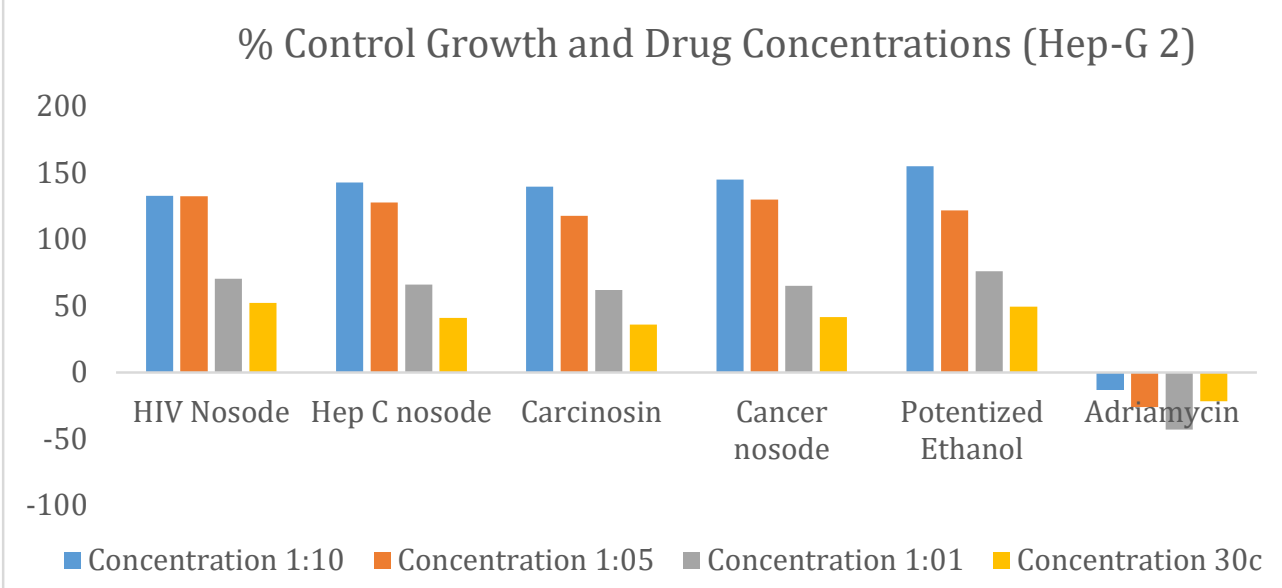

Figure $1 \%$ Control Growth and Drug Concentrations (HeLa)

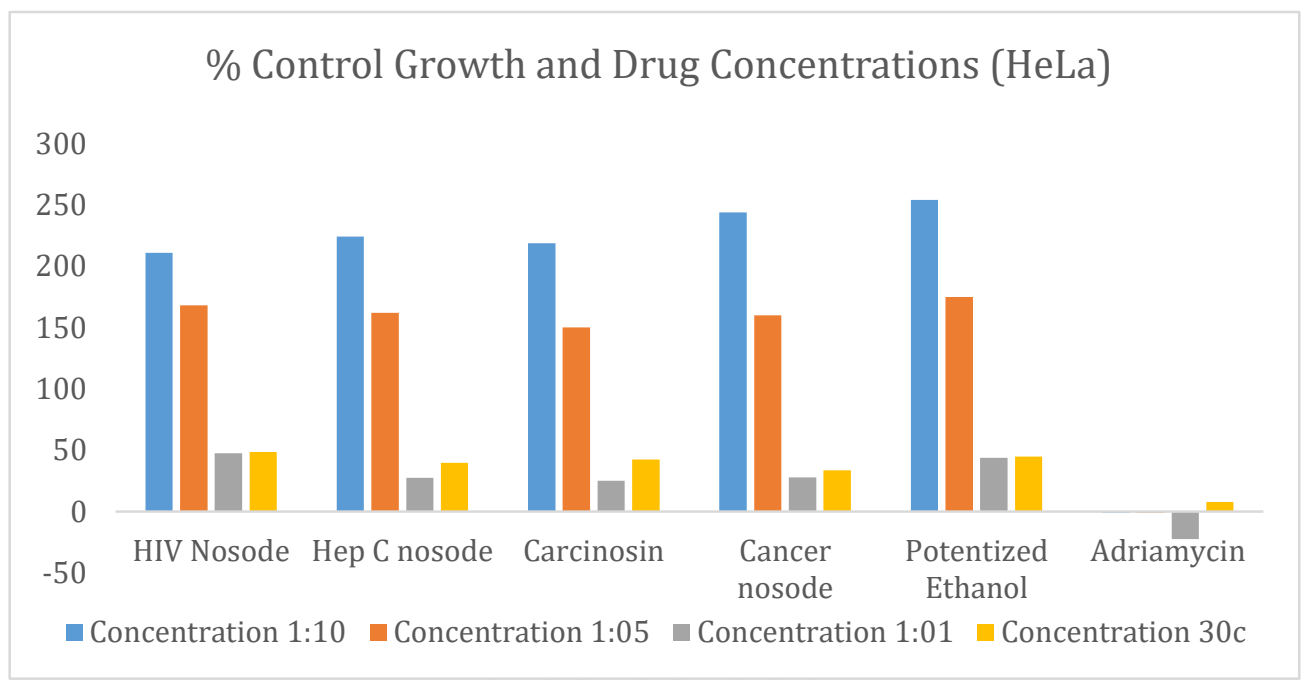

Figure2 \% Control Growth and Drug Concentrations (Hep-G2)

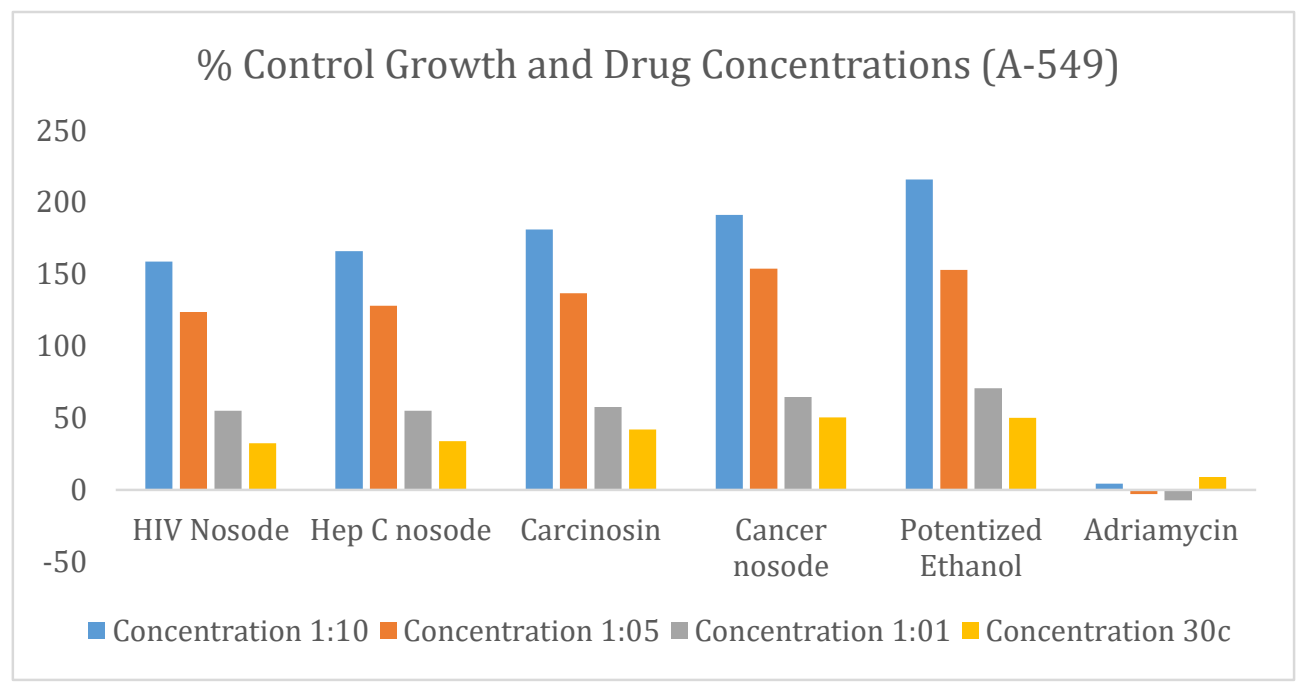

Figure $3 \%$ Control Growth and Drug Concentrations (A-549) 


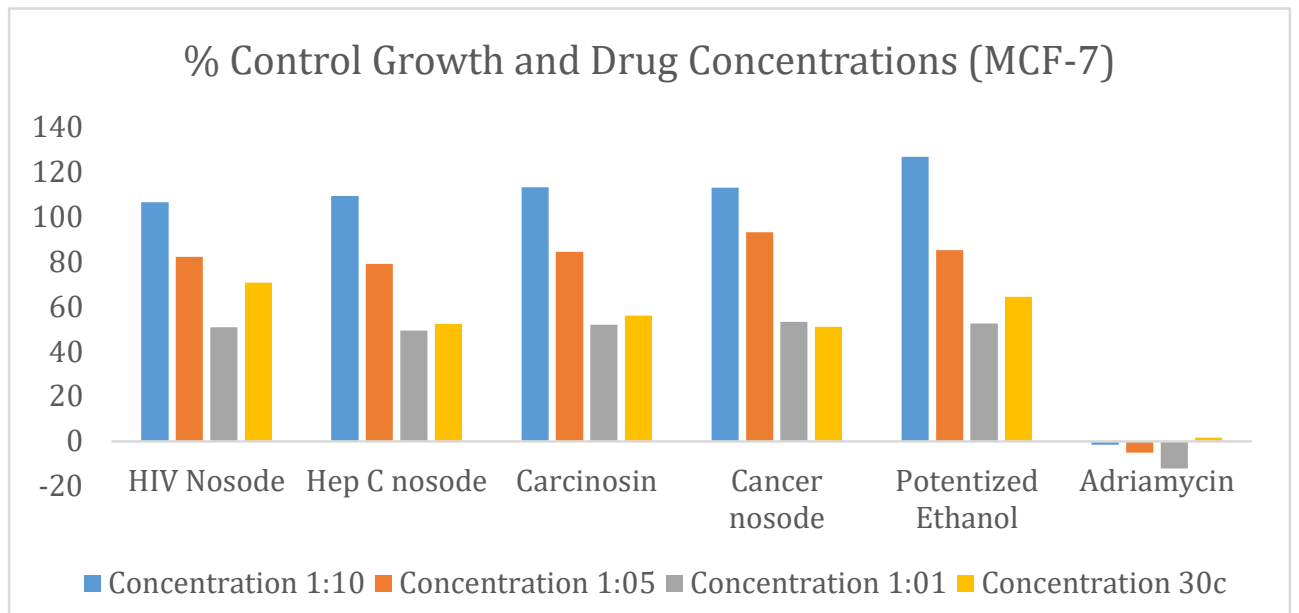

Figure $4 \%$ Control Growth and Drug Concentrations (MCF-7)

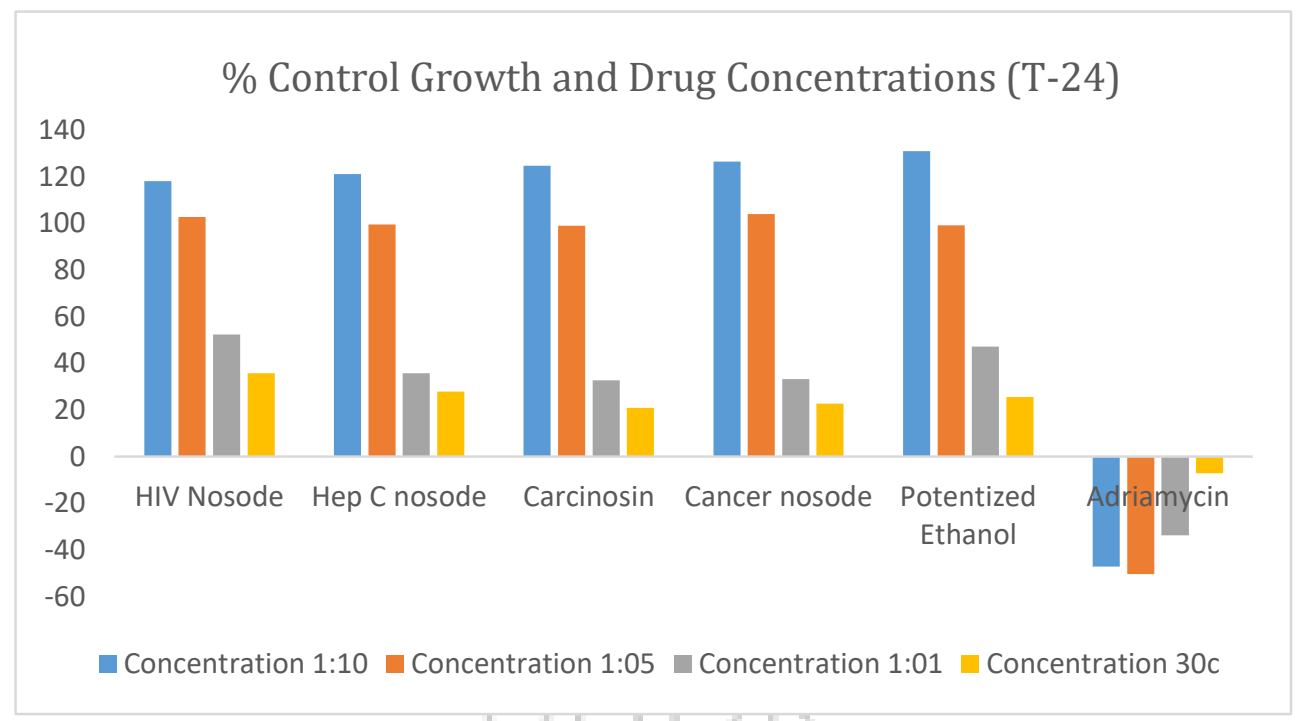

Figure $5 \%$ Control Growth and Drug Concentrations (T-24)

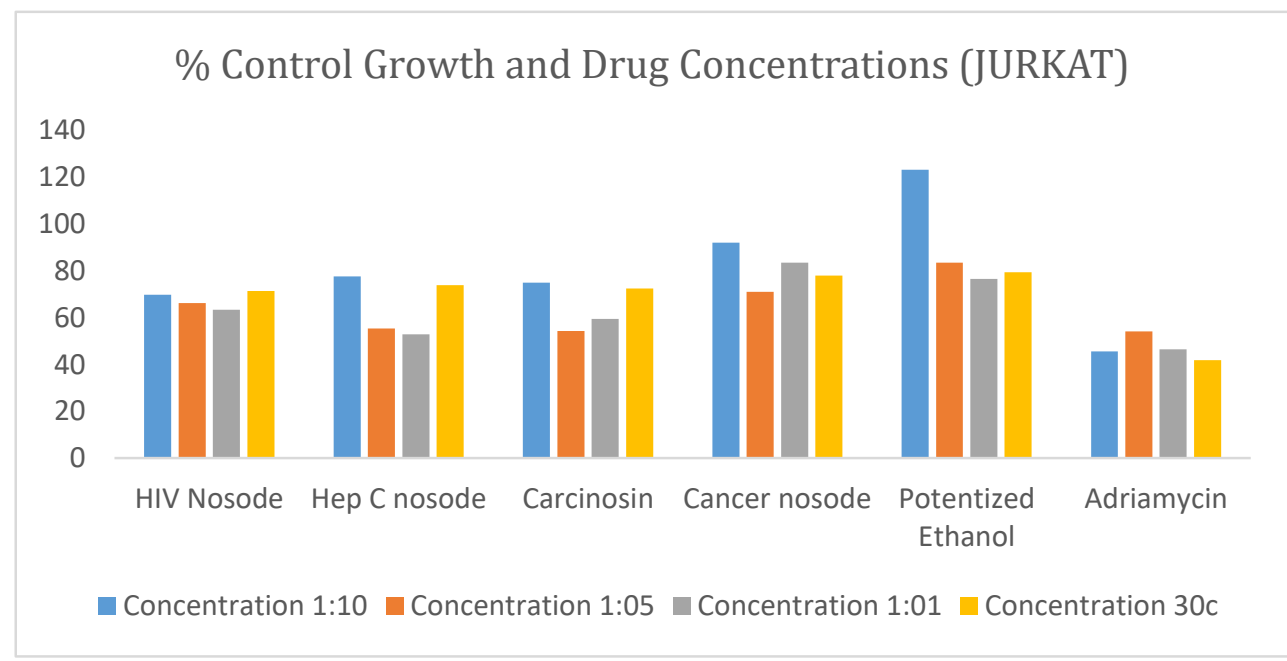

Figure $6 \%$ Control Growth and Drug Concentrations (JURKAT) 


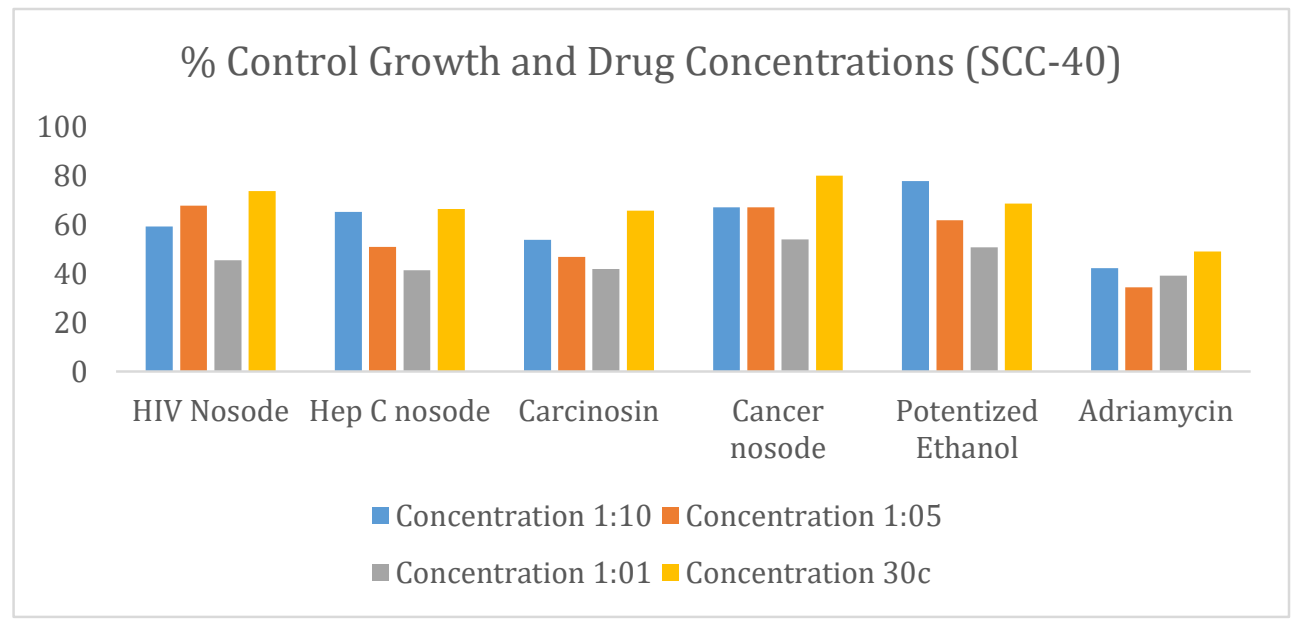

Figure $7 \%$ Control Growth and Drug Concentrations (SCC-40)

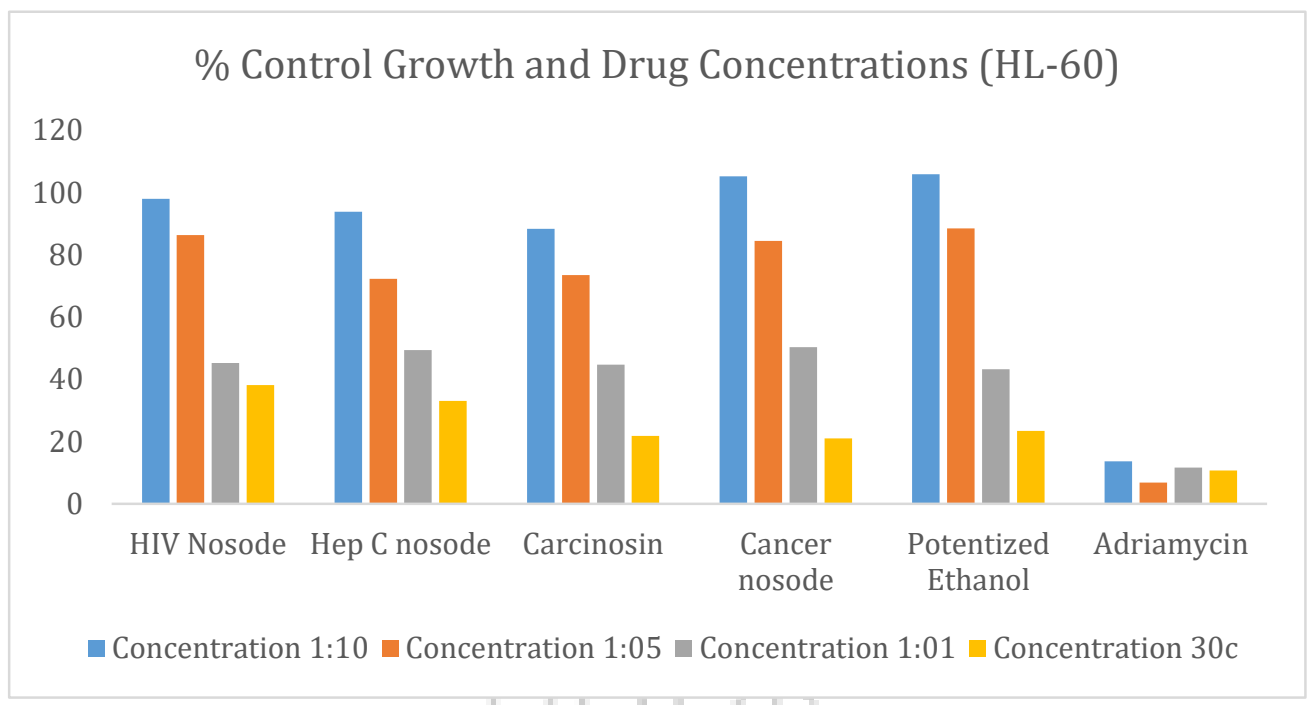

Figure $8 \%$ Control Growth and Drug Concentrations (HL-60)

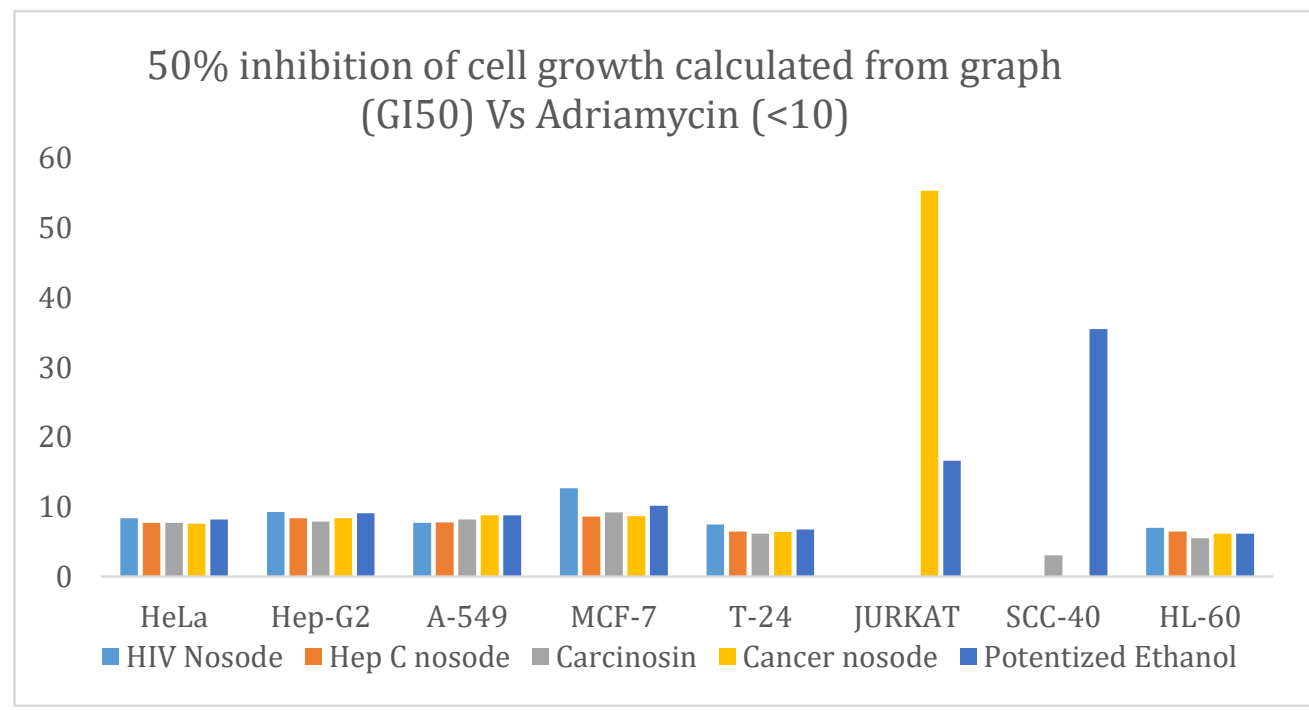

Figure 9 Concentration of drug causing 50\% inhibition of cell growth (Graph G-150) 


\section{Human cervical cancer cell line (HeLa)}

All the five homeopathy

preparations have shown the anticancer activity on Human cervical cancer cell line HeLa. (figures 10, 1 and 9).

Figure 10 Growth curve- Human Cervical cancer cell line (HeLa)

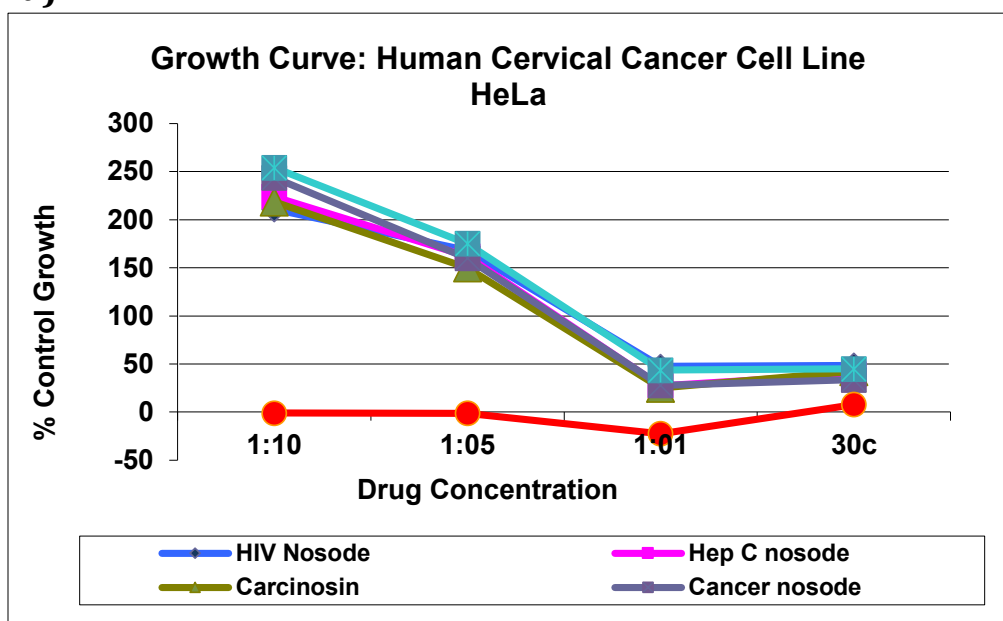

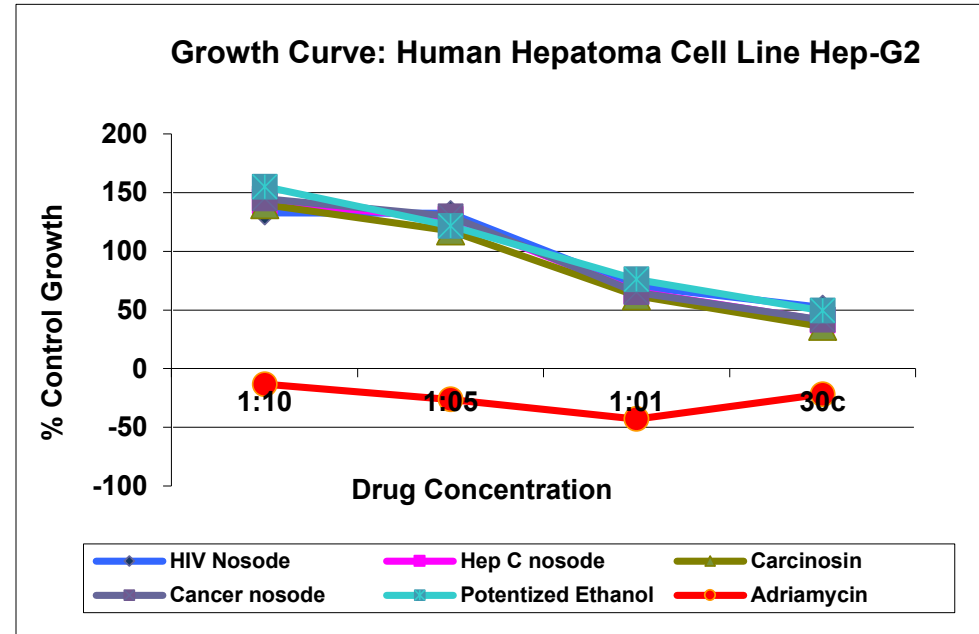

Human Hepatoma Cell Line Hep-G2

All the five homeopathy preparations have shown the anticancer activity on human hepatoma cell line (Hep-G2). (Figures 11, 2 and 9).

Figure 11 Growth curve- Human Hepatoma cell line (Hep-G2)

\section{Human Lung Cell Carcinoma Cell A-549:}

All the five homeopathy preparations have shown the anticancer activity on human lung cell carcinoma cell (A-549) (Refer figure 12, 3 and 9).

Figure 12 Growth curve-Human lung cell carcinoma cell (A-549)

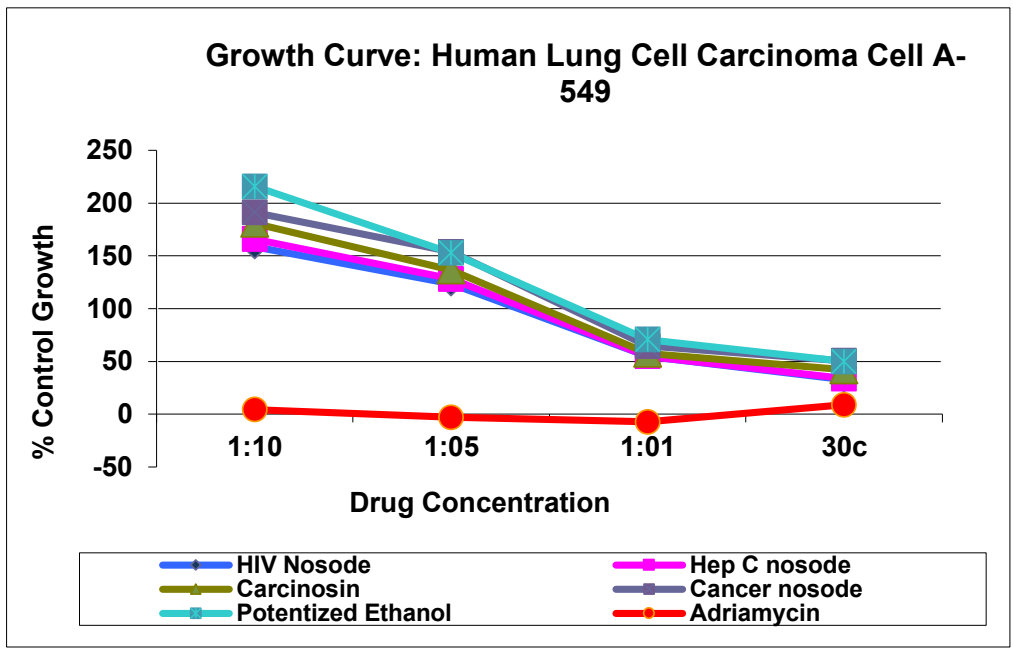




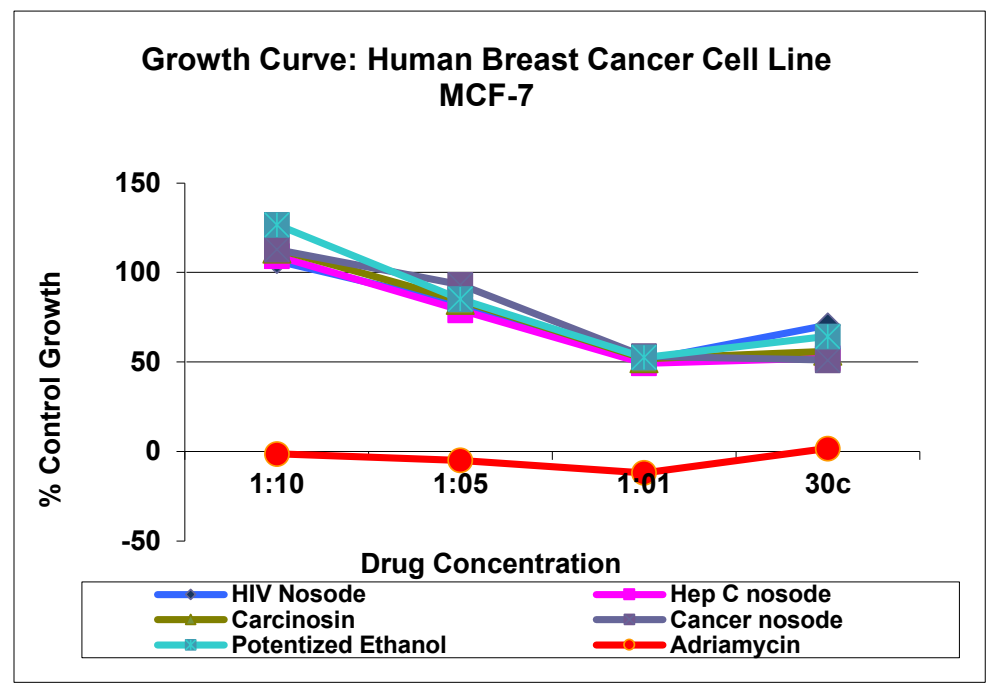

Human Breast Cancer Cell Line MCF-7

Hepatitis C, Carcinosin, and Cancer nosode have shown the anticancer activity on breast cancer cell line MCF7 (Figures 13, 4 and 9).

Figure 13 Growth curve- Human breast cancer cell line MCF-7

\section{Human Bladder Cancer Cell Line T- 24}

All the five homeopathy preparations have shown the anticancer activity on human bladder cancer cell line (T-24) (Figures 14, 5 and 9).

Figure 14 Growth curve-human bladder cancer cell line (T-24)
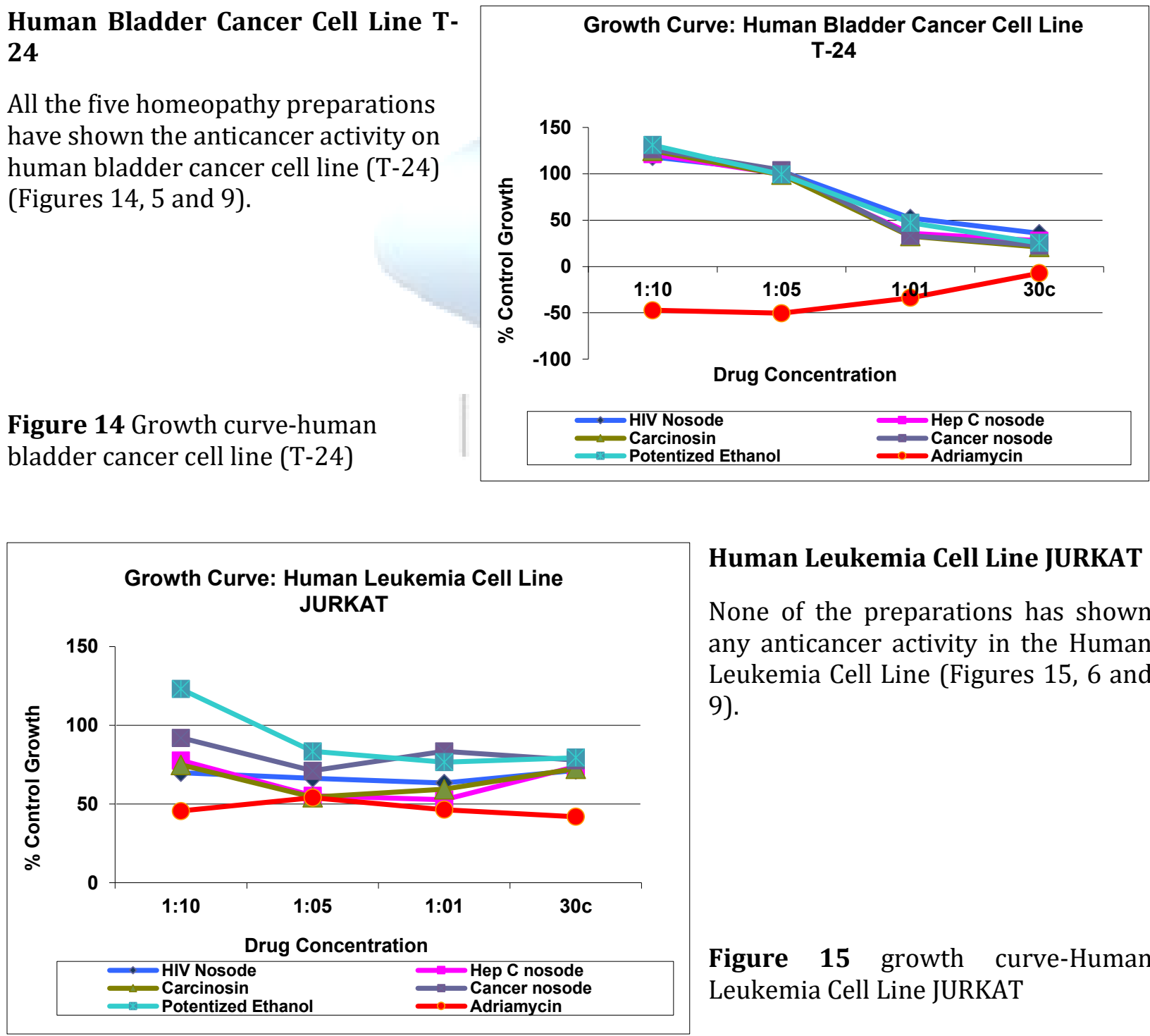

Human Leukemia Cell Line JURKAT

None of the preparations has shown any anticancer activity in the Human Leukemia Cell Line (Figures 15, 6 and 9).

Figure 15 growth curve-Human Leukemia Cell Line JURKAT 
Available online at www.highdilution.org

Human Oral Squamous Cell Line (SCC-40)

Only Carcinosin has shown the anticancer activity in the oral squamous cell line (Figures 16, 7 and 9).

Figure 16 Growth curve- Human oral squamous cell line (SCC-40)
Growth Curve: Human Oral Squamous Cell Line SCC-40

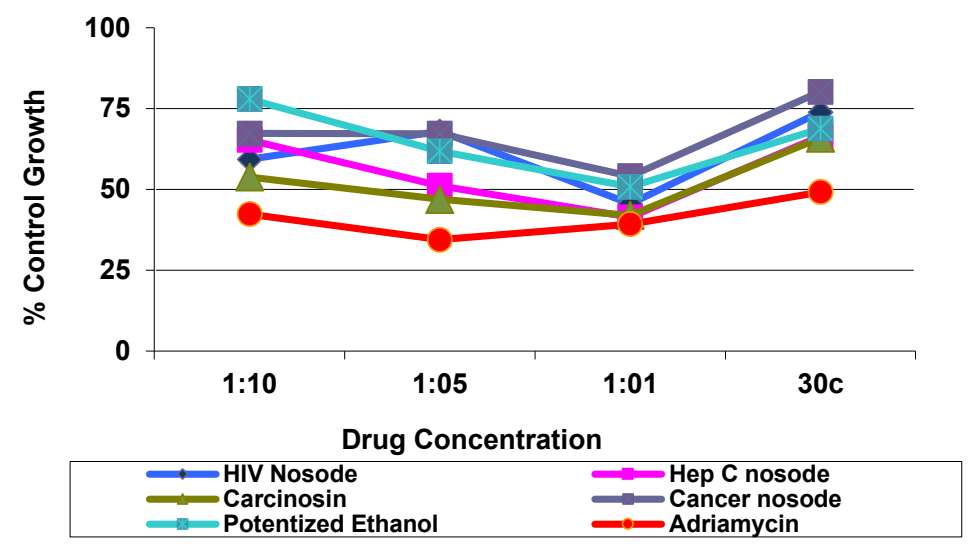

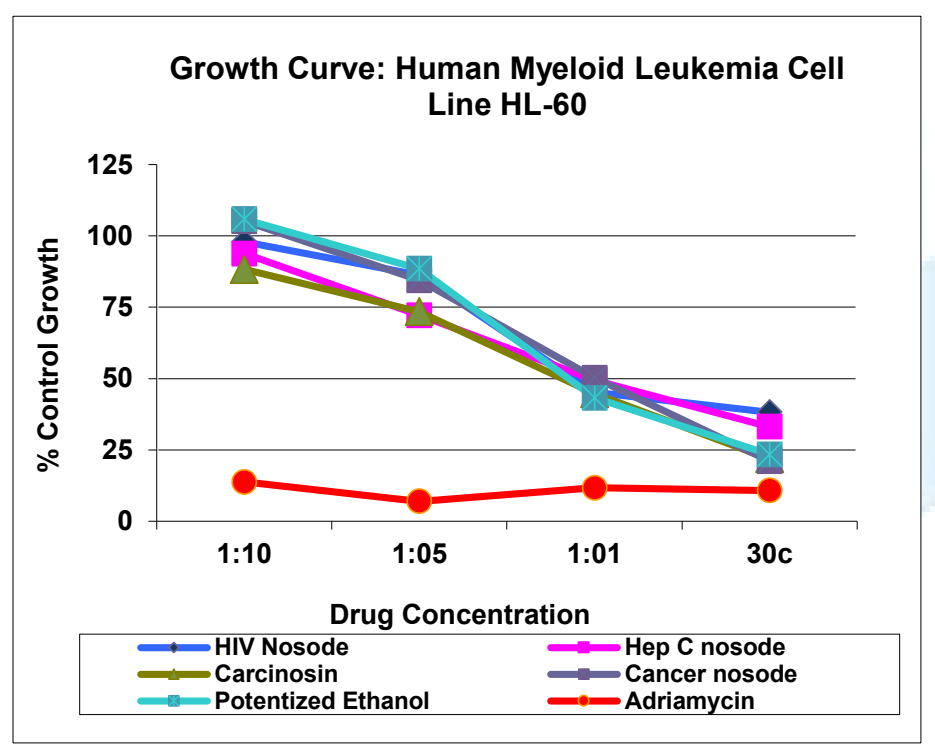

Human Myeloid Leukemia Cell Line HL60

All the five preparations have shown the anticancer activity on the Human Myeloid Leukemia cell line. (Figures 17, 8 and 9).

Figure 17 growth curve- Human Myeloid Leukemia cell line (HL-60)

The high-dilutions can be prepared by potentization using either alcohol or water (Water for injection- WFI) as a medium. Another set of high dilution preparations of all the test drugs was prepared separately using water (WFI) as a vehicle for undertaking a study to see the difference in results, if any. The preparations thus made were tested on the Human Lung Cancer cell line (A-549); only one cell line was used to check if the nature of the vehicle has any impact on the activity. No anticancer activity was observed in any of the test drugs prepared using the WFI as a vehicle. Similarly, to determine if it is the effect of alcohol or the process of potentization that produced the anticancer effect, another study was conducted to examine the impact of Ethanol (without potentization) on the Human Lung Cancer cell line (A-549). The un-potentized alcohol did not show any anticancer activity on A-549. (figure 18 and table 1) 


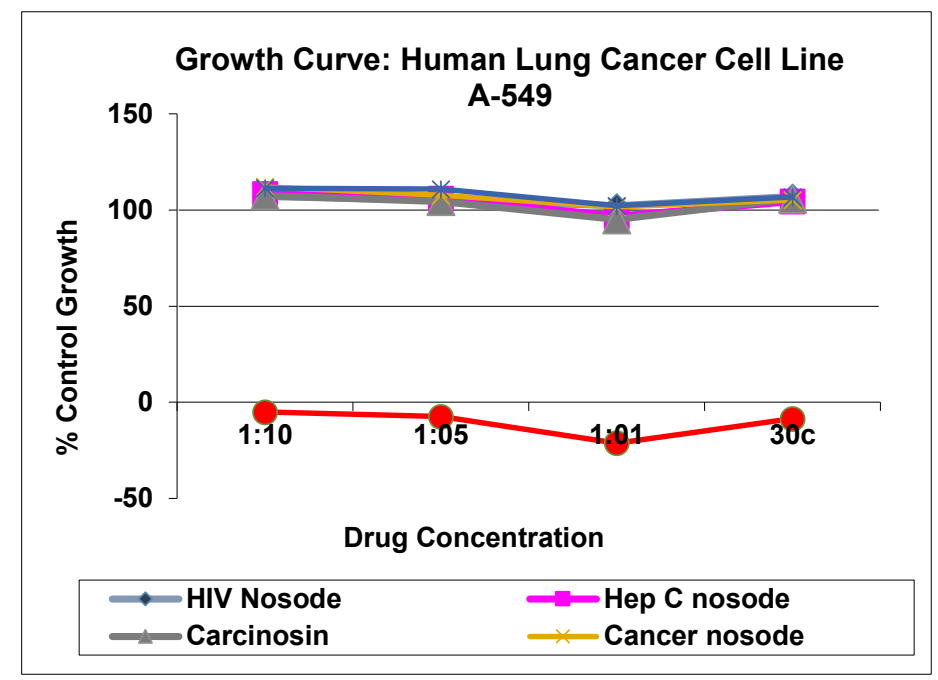

Figure 18: Growth curve of A-549

Table 1: Results for water-based preparations and un-potentized alcohol on Human Lung Cancer cell line (A-549)

\begin{tabular}{|c|c|c|c|c|c|}
\hline Medicine & $\%$ Contr & wth and & ug Con & trations & Drug concentrations $(\% \mathrm{v} / \mathrm{v})$ \\
\hline$\% \mathrm{v} / \mathrm{v}$ & 1 & 2 & 3 & 4 & GI50 \\
\hline HIV Nosode & 107.1 & 105.1 & 102.2 & 107.1 & $>10$ \\
\hline Hep C nosode & 108.5 & 106.1 & 96.8 & 104.5 & $>10$ \\
\hline Carcinosin & 107.5 & 104.4 & 95.1 & 105.9 & $>10$ \\
\hline Cancer nosode & 112.0 & 107.6 & 101.6 & 105.2 & $>10$ \\
\hline $\begin{array}{l}\text { Un-potentized } \\
\text { alcohol }\end{array}$ & 111.4 & 110.9 & 102.2 & 106.7 & $>10$ \\
\hline Adriamycin & -5.0 & -7.4 & -21.2 & -8.5 & $<10$ \\
\hline
\end{tabular}




\section{Discussion}

The research evaluates the efficacy of the high-dilution and potentized medicines, that too, in the lab models outside of the human system, is relatively novel. The controlled study has shown three homeopathic drugs sourced from carcinogens such as HIV virus, Hepatitis C virus, and Ethanol; and two from cancer tissues (new Cancer nosode, and Carcinosin) in high dilutions (Potentized) having variable anticancer activities in Human cervical cancer (HeLa), Hepatoma (HepG2), Lung cell carcinoma A 549, Bladder cancer T 24 and Myeloid Leukemia HL-60.

On investigative communication by the author with some of the leading manufactures of Carcinosin nosodes, it was found that the currently available nosode is often a mix of over 28 different cancer tissues, of which no source details are available with the manufactures [24]. Therefore, the author has prepared a new Cancer Nosode from well-defined tissues using five different cancers (The article is under review for publication.)

The New Cancer nosode has shown anticancer effects on HeLa, Hep-G2, A-549, MCF-7, T-24, and HL60 cell lines, while Carcinosin has shown results against HeLa, Hep-G2, A-549, MCF-7, T-24, SCC-40, and HL-60, which may be due to a broader spectrum of cancer tissues. More studies with individual tissues as well as multiple tissues may prove more insightful.

Only Carcinosin has shown anticancer activity in the oral squamous cell line (SCC-40). None of the homeopathic preparations has shown any anticancer activity in Human Leukemia Cell Line (Jurkat). Hepatitis $\mathrm{C}$ nosode, Carcinosin, and Cancer nosode have demonstrated the anticancer activity against breast cancer cell line MCF-7.

Potentized Ethanol has shown anticancer activity in HeLa, Hep-G2, A-549, T-24, and HL-60 cell lines. However, an additional study using the un-potentized Ethanol did not show any anticancer effect in A-549 cell line, suggesting the role of potentization in rendering the therapeutic impact of unpotentized alcohol, while the Potentized Ethanol did show anticancer activity on the same cell line. Potentized Ethanol has not shown any activity in MCF-7 and SCC 40 cell lines. In contrast, Hepatitis $\mathrm{C}$ nosode, Cancer nosode (both were Potentized using the same Ethanol as a vehicle), and Carcinosin have shown activity in MCF-7 and Carcinosin in SCC 40. This suggests that the positive effect in all the three nosodes was not due to the Potentized Ethanol but due to the respective Potentized source materials. This finding was supported by the outcome of the study done in the past where HIV nosode and Hepatitis C nosode have shown anticancer activity on MCF-7 and A549 cell lines as compared to Potentized Ethanol [14,15].

When made using water (Water for injection) as a medium instead of alcohol, the same preparations did not show any anticancer activity. This observation suggests that alcohol as a medium seems to retain the therapeutic properties of the original drug substance better than only water. Literature indicates the use of ethanol-water for serial dilutions. Many theories have been put up to describe the role of water-ethanol clusters, transfer of information of specific remedy material in waterethanol colloidal solution [25].

HIV [26], Hepatitis C virus [27], and Potentized Ethanol [28,29] are known carcinogens. The Cancer tissues are end products of the malignant process, including a wide range of proteins, debris, cytokines, immunocytes, cells, and more. The ultra-diluted preparations of all of these carcinogens and cancer tissues have shown anticancer effects. More carcinogens and cancer tissues using more cell line models and in-vivo studies may lead to understanding the mode of actions.

\section{Conclusion}

High dilution, potentized preparations of certain carcinogens have demonstrated anti-cancer, cytotoxic effects in the cell-line model, supporting the rationale of the fundamental homeopathic principle the Law of Similars, opening windows to its broader applications in healthcare. 


\section{Acknowledgments}

Sincere thanks to Tata Memorial Centre, Navi Mumbai. In-vitro SRB assay for anticancer activity evaluation of drugs, was done at Anticancer Drug screening facility (ACDSF) at ACTREC, Tata Memorial Centre, Navi Mumbai.

\section{References}

[1] Bishayee K, Mondal J, Sikdar S, Khuda-Bukhsh AR. Condurango (Gonolobus condurango) Extract Activates Fas Receptor and Depolarizes Mitochondrial Membrane Potential to Induce ROS-dependent Apoptosis in Cancer Cells in vitro: CE-treatment on HeLa: a ROS-dependent mechanism. J Pharmacopuncture. 2015 Sep;18(3):32-41. doi: 10.3831/KPI.2015.18.022. PMID: 26389000

[2] Mondal J, Samadder A, Khuda-Bukhsh AR. Psorinum $6 \times$ triggers apoptosis signals in human lung cancer cells. J Integr Med. 2016 Mar;14(2):143-53. doi: 10.1016/S20954964(16)60230-3. PMID: 26988436

[3] Frenkel M, Mishra M, Sen S, Yang P, Pawlus A, Vence L, Leblanc A, Cohen L, Banerji P, Banerji P. Cytotoxic effects of ultra-diluted remedies on breast cancer cells. Int J Oncol. 2010 Feb;36(2):395-403.

[4] Sikdar S, Mukherjee A, Bishayee K, et al. Post-cancer Treatment with Condurango 30C Shows Amelioration of Benzo[a]pyrene-induced Lung Cancer in Rats Through the Molecular Pathway of Caspase-3-mediated Apoptosis Induction -Anti-lung cancer potential of Condurango 30C in rats-. Journal of Pharmacopuncture. 2013;16(3):11-22. doi:10.3831/kpi.2013.16.021.

[5] Shilpi Saha, Dewan Md Sakib Hossain, Shravanti Mukherjee, Suchismita Mohanty, Minakshi Mazumdar, Sanhita Mukherjee, Uttam K Gosh, Chaturbhuj Nayek, Chinta Raveendar, Anil Khurana, Rathin Chakrabarty, Gaurisankar Sa, and Tanya Das. Calcarea carbonica induces apoptosis in cancer cells in p53-dependent manner via an immunomodulatory circuit. BMC Complement Altern Med. 2013; 13: 230. doi: 10.1186/1472-688213-230 PMCID: PMC3856502

[6] Riedel S, Edward Jenner and the history of smallpox and vaccination, Proc (Bayl Univ Med Cent). 2005 Jan; 18(1): 21-25. PMCID: PMC1200696. Available from: https://www.ncbi.nlm.nih.gov/pmc/articles/PMC1200696/ accessed on 2nd Jan 2018

[7] Shah R, Scientific method of preparing homoeopathic nosodes. Indian J Res Homoeopathy [Serial Online] 2014; 8: $166 \mathrm{e} 174$ [cited 2014 Oct 21]. Available from: http://www.ijrh.org/text.asp?2014/ 8/3/166/141740

[8] Shah R. Clinical trial for evaluation of a Human Immunodeficiency Virus nosode in the treatment for Human Immunodeficiency Virus-Infected individuals. Indian J Res Homoeopathy. $2015 ; 9: 25-33$ 
[9] Shah R. A Clinical Evaluation of a Hepatitis C Nosode in the Treatment of Hepatitis C. The Journal Of Alternative And Complementary Medicine, Vol. 22, 3, 2016, pp. 197-203. DOI: 10.1089/acm.2014.0146

[10] Joshi S, Munshi R, Talele G, Shah R. An experimental in vitro study to evaluate the antimalarial activity of select homeopathy preparations. International Journal of Medical and Health Research. Volume 3; Issue 7; July 2017; Page. 65-68. Available from: www.medicalsciencejournal.com

[11] HIV infection and cancer risk. https://www.cancer.gov/about-cancer/causesprevention/risk/infectious-agents/hiv-fact-sheet. Accessed on 6th Dec 2017

[12]Hepatitis $\quad \mathrm{C}$ fact sheet Updated 2017. http://www.who.int/mediacentre/factsheets/fs164/en/. Accessed on 6th Dec 2017

[13] Cogliano, VJ; Baan, R; Straif, K; Grosse, Y; Lauby-Secretan, B; El Ghissassi, F; Bouvard, V; Benbrahim-Tallaa, L; Guha, N; Freeman, C; Galichet, L; Wild, CP (Dec 21, 2011). "Preventable exposures associated with human cancers". Journal of the National Cancer Institute. 103 (24): 1827-39. doi:10.1093/jnci/djr483. PMC 3243677. PMID 22158127

[14] IARC monographs on the evaluation of carcinogenic risks to human. List of classifications volumes 1-120. Available online at http://monographs.iarc.fr/ENG/Classification/latest_classif.php accessed on 2nd Jan 2018

[15] Bukhsh AR, Shah R, Mondal J. Therapeutic potential of HIV nosode 30c as evaluated in A549 lung cancer cells. Homeopathy (2017) 106, 203e213. https://doi.org/10.1016/j.homp.2017.09.001, Available online at http://www.sciencedirect.com accessed on 26th Dec 2017

[16] Bukhsh AR, Shah R, Das J, Mondal J. A homeopathic nosode, hepatitis C demonstrates anticancer effect against liver cancer cells in vitro by modulating telomerase and topoisomerase II activities as also by promoting apoptosis via intrinsic mitochondrial pathway. Journ al of Integrative Medicine, May 2016, Vol.14, No.3.pp 209-18, http:// dx.doi.org/ 10.1016/ $\underline{\text { S2095-4964(16)60251-0 }}$

[17] Florento L, Matias R, Tuaño E, Santiago K, CruzF, Tuazon A. Comparison of Cytotoxic Activity of Anticancer Drugs against Various Human Tumor Cell Lines Using In Vitro CellBased Approach. Int J Biomed Sci. 2012 Mar; 8(1): 76-80. PMCID: PMC3614850. Available at https://www.ncbi.nlm.nih.gov/pmc/articles/PMC3614850/ accessed on 4th Jan 2018

[18] Methods Mol Biol.2013;1055:191-205. doi: 10.1007/978-1-62703-577-4_14. Bioassays for anticancer activities. McCauley J1, Zivanovic A, Skropeta D. DOI: 10.1007/9781-62703-577-4_14 , Available at; $\underline{\text { https://www.ncbi.nlm.nih.gov/pubmed/23963912 }}$ 
[19] Voigt W. Sulforhodamine B assay and chemosensitivity. Methods Mol Med. 2005;110:39-48. DOI: 10.1385/1-59259-869-2:039 available at: https://www.ncbi.nlm.nih.gov/pubmed/15901925

[20] Methods in Molecular Medicine, vol. 110: Chemosensitivity: Vol. 1: In Vitro Assays Edited by: R. D. Blumenthal (C) Humana Press Inc., Totowa, NJ

[21] Vanicha V, Kanyawim K. Sulforhodamine B colorimetric assay for cytotoxicity screening Nature Protocols 1, - 1112 - 1116 (2006)

[22] Shah R. Scientific method of preparing homoeopathic nosodes. Indian J Res Homoeopathy $2014 ; 8: 166-74$

[23] Esteban A. Orellana. Andrea L. Kasinski. Sulforhodamine B (SRB) Assay in Cell Culture to Investigate Cell Proliferation. Bio Protoc. 2016 Nov 5; 6(21): e1984.

https://www.ncbi.nlm.nih.gov/pmc/articles/PMC5448418/pdf/nihms844985.pdf

[24] Communication with Nelson, US, Helios, UK; Hapco, India.

[25] Iris R, Bell I, Koithan M. A model for homeopathic remedy effects: low dose nanoparticles, allostatic cross-adaptation, and time-dependent sensitization in a complex adaptive system. BMC Complementary and Alternative Medicine 2012, 12:191. http://www.biomedcentral.com/1472-6882/12/191.

[26] American Cancer Society. Known and Probable Human Carcinogens. Available at https://www.cancer.org/cancer/cancer-causes/general-info/known-and-probablehuman-carcinogens.html accessed on 26th Dec 2017.

[27] Lemon S M, David R, Mc Givern. Is Hepatitis C Virus Carcinogenic? Gastroenterology. 2012 May; 142(6): 1274-1278. doi: 10.1053/j.gastro.2012.01.045. Available at https://www.ncbi.nlm.nih.gov/pubmed/22537433 accessed on 26th Dec 2017.

[28] Alcohol and cancer risk. National institute for health. Available at https:// www.cancer.gov/about-cancer/causes-prevention/risk/alcohol/alcohol-fact-sheet accessed on 26th Dec 2017.

[29] Pöschl G, Seitz HK. Alcohol and cancer. Alcohol. 2004 May-Jun;39(3):155-65. Available at https://www.ncbi.nlm.nih.gov/pubmed/15082451 accessed on 26th Dec 2017.

Received: 3 may, 2019. Accepted: 18 june, 2019. 
(C) International Journal of High Dilution Research.

Not for commercial purposes. 